light of frequency equal to that of the absorption line. This condition was perfectly fulfilled by the vapour of mercury, which has an absorption line at $\lambda=2536$ in the ultra-violet.

If a beam of monochromatic light of this wavelength was focussed at the centre of an exhausted quartz bulb containing a drop of mercury at atmospheric temperature, it was found that the light was powerfully scattered by the vapour, photographs of the bulb made with a quartz lens showing the cone of rays much as if the bulb were filled with smoke. The scattered light is invariably much more homogeneous than the incident beam, in which the "line" has a finite width, whereas the scattered light corresponds only with the centre of this line. "The rest gets through the vapour unaffected. With the light thus scattered-the resonance radiation-a photograph was made of a quartz bulb containing a minute drop of mercury at room temperature. The bulb appeared as if filled with ink owing to the opacity of the vapour for the rays.

These phenomena, visible only to the camera, can be visually reproduced in the case of sodium vapour excited by the light from a sodium flame. If the density of the vapour is increased by warming it, the distance which the light can penetrate into the bulb is diminished and eventually the resonance radiation is all emitted from a region so close to the surface that it appears as a bright yellow patch on the inner surface of the glass.

If this patch is now used as a lamp, and focussed by a concave mirror on the surface of the same globe (or another in which the vapour is of sufficient density to give the patch effect) so as to fall partly on a surface whitened by deposited magnesia and partly on the enclosed vapour, the brightness of the two contiguous patches thus formed is practically equal.

This proves that, under those conditions, at comparatively low densities, true absorption does not exist, the light abstracted from the incident beam being reemitted as light of the same wave-length but in all directions.

The factor of true absorption makes itself manifest as soon as we admit air or some other foreign gas. Even if the pressure is only a millimetre or two the effect is very marked.

Another point which can be brought out by this method of attack is whether or not the mechanisms the vibration frequencies of which correspond to the various lines in a spectrum are independent of each other or are interconnected.

An ingenious method was described whereby a beam of considerable intensity, consisting, however, of only $D_{1}$ or $D_{2}$ light, could be obtained, and if the sodium vapour excited by either of these was examined spectroscopically the emitted light contained only that one of the lines which was used to excite it. This shows that the $D_{1}$ and $D_{2}$ mechanisms are quite independent. In other cases, however, vapours excited by light of any one line of their spectrum gave out a resonance spectrum of that line and one or more others showing that some groups of mechanisms were interdependent and could not be excited separately.

Stimulation by Waves of Very Short Wave-Length. -Experiments were then described in which air, nitrogen, etc., had been caused to emit ultra-violet light when exposed to the action of radiation of wavelength less than the Schumann rays, the smallest waves hitherto known. Schumann rays were completely absorbed by quartz, but would pass through a considerable thickness of fluorite, but the rays to which he referred could be reduced in intensity by 98 per cent. by a plate of fluorite $1 \mathrm{~mm}$. thick.

Nitrogen was more actively stimulated than air by these rays, as oxygen seemed to have a destructive effect on the phenomena. Thus iodine vapour, if mixed with nitrogen, emitted a green light under the action of the rays, while remaining dark if mixed with oxygen.

He urged the necessity of an exact mathematical treatment of the phenomenon of a molecule of vapour re-enitting radiation which it has abstracted from an incident beam, truc absorption being absent.

At the conclusion of the lecture a number of interesting experiments illustrative of the subject of the lecture were shown. These included the resonance radiation of sodium stimulated by $D$ light, of iodine vapour stimulated by the light from a quartz-mercury lamp, and of the author's method of extinguishing one of the $\mathrm{D}$ lines from the light from a sodium flame.

\section{STRUCTURAL ANALOGIES BETWEEN IGNEOUS ROCKS AND METALS.}

I T was in Sheffield that the late Dr. H. C. Sorby lived and worked. It was to the Sheffield Literary and Philosophical Society that, in 1864 , Sorby presented the first account of his microscopical examination of the structures of commercial steel. In Sheffield the worth of Sorby's work is now being recognised, and during the presidency of Mr. Arthur Balfour the Sheffield Society of Engineers and Metallurgists, an active and growing society closely associated with the industries of the city, has founded the "Sorby Lecture," to "mark its progress," and to perpetuate the memory of its late honorary member.

The first Sorby Lecture, on February 28, was the occasion for a large gathering of Sheffield's leading manufacturers and citizens at the Cutlers' Hall. The lecture was delivered by Prof. W. G. Fearnsides, the occupant of the Sorby chair of geology at Sheffield University, "On Some Structural Analogies between Igneous Rocks and Metals."

In the first part of the lecture Prof. Fearnsides traced the progressive development of the research by which Sorby, already trained to a knowledge of optics and of chemistry, learned from Williamson the art of making transparent sections of hard objects, and applied it (1849) to the study of rocks. Limestones were the first rocks to claim his attention (185I), then slates ( 1856 ), and then igneous rocks (1857), and from these, through meteorites (1862), he was led to study irons $\left(1863_{-4}\right)$. The difficulties which Sorby encountered and his patient toil, continued in defiance of indifference and ridicule, were discussed, and it was conjectured that the apathy with which his results were received was due to his own inability to appreciate the difficulties which his refined technique and the vector variations of the optical properties of minerals presented to other people.

The recognition of the value of Sorby's petrographic methods grew gradually through the sixties and seventies of last century, but it was not until after his announcement to the Iron and Steel Institute in I886, that in the previous year a new microscope had enabled him to see the true composite nature of the "pearly constituent" of steel, that his pioneer work on metals attracted any attention.

It was by a fortunate but unforeseen coincidence that the first Sorby Lecture was delivered within a few days of the fiftieth anniversary of the day on which Sorby read the first of all papers dealing with the micro-structure of commercial metals, and the subject for the lecture was chosen accordingly.

The second part of the lecture dealt with the modern view that igneous rocks and metals are alike products derived by progressive partition of components during the crystallisation of mixed solutions. Being thus

NO. 23I5, VOL. 93] 
homologous in the manner of their origin, it was maintained that a mineralogical nomenelature which is properly applicable to the constituents of igneous rocks is similarly applicable to the constituents of steel; and though a phase rule (temperature-concentration) diagram affords a ready means for the discussion of the behaviour of phases during their partition into other pairs of phases, a metallographic description of their structure modelled on the nomenclature usual in petrography is more manageable when the number of constituents is large.

Special analogies between igneous rocks and metals were suggested. Segregation of the phosphorus and the sulphur in steel ingots was paralleled with "differentiation-in-situ" as it occurs in igneous rocks. The time taken in cooling through the temperature range of active crystal growth was shown to control the texture both of igneous rocks and of metals. Viscosity as another factor controlling crystal growth was considered, and the absence of any structures in metals analogous to those developed in viscous rock magmas and in devitrifying glass-e.g. "spherulitic structure"-was attributed to essential differences in this respect. "Skeletal crystals," so common in metals, are characteristic of over-rapid growth and as a passing stage in the development of polyhedra are not unknown in rocks.

"Eutectic structures" in metals are like the "graphic" and "pegmatitic" structures of rocks, and their obliteration with slower cooling, both from rocks and metals, was noted.

"Cores" in "mixed crystals" of metals are analogous to "zonary banding" in non-homogeneous isomorphous minerals, and the successive crystallisation of distinct phases above and below a change-point has its parallel in the "corona structure" of some norites.

Partition of solid solutions always at the margins or along the cleavage of pre-existing crystal grains, a process so important in the heat treatment of commercial steels, finds its analogue in the orderly separation of the "schiller constituents" within the minerals of plutonic rocks. "Perthitic structure" in slowcooled felspars seems to require a similar explanation.

From analogies such as these it was argued that the experience of the geologist may be useful to the metallurgist, and that the knowledge of the structure of metals, which for commercial purposes are manufactured under controlled conditions of temperature and of stress, may provide a key of great adaptability with which, in conjunction with his map, his hammer, and his microscope, the geologist may decipher and interpret the autobiographical secrets of the record contained in the rocks

\section{INDUSTRIAL RESEARCH IN AMERICA. ${ }^{1}$}

GERMANY has long been recognised as pre$G$ eminently the country of organised research. The spirit of research is there immanent throughout the entire social structure. This is not the time or place, however, nor is it necessary before this audience, to refer in any detail to the long record of splendid achievement made by German research during the last fifty years. It is inscribed in luminous letters around the rock upon which Germany now stands secure among the nations of the world.

The virility and range of German research were never greater than they are to-day. Never before have the superb energy and calculated audacity of German technical directors and German financiers transformed so quickly and so surely the triumphs of the labora-

1 From the presidential address delivered before the Ametican Chemical Society at Rochester, New York, Septemher 9, r9r3, by Arthur D. Little. NO. 23I5, VOL. 93] tory into industrial conquests. Never has the future held richer promise of orderly and sustained progress, and yet the pre-eminence of Germany in industrial research is by no means indefinitely assured. A new competitor is even now girding up his loins and training for the race, and that competitor is, strangely enough, the United States-that prodigal among nations, still justly stigmatised as the most wasteful, careless, and improvident of them all.

To one at all tamiliar with the disdain of scientific teaching which has characterised our industry, and which still persists in many quarters, this statement is so contrary to the current estimate that its general acceptance cannot be expected. It will have served its purpose if it leads to a consideration of the facts which prove the thesis.

The country of Franklin, Morse, and Rumford, of McCormick, Howe, and Whitney, of Edison, Thomson, Westinghouse, and Bell, and of Wilbur and Orville Wright, is obviously a country not wholly hostile to industrial research or unable to apply it to good purpose. It is, however, not surprising that with vast areas of virgin soil of which a share might be had for the asking, with interminable stretches of stately forest, with coal and oil and gas, the ores of metals, and countless other gifts of nature scattered broadcast by her lavish hand, our people entered upon this rich inheritance with the spirit of the spendthrift, and gave little heed to refinements in methods of production and less to minimising waste. That day and generation are gone. To-day their children, partly through better recognition of potential values, but mainly by the pressure of a greatly increased population and the stress of competition between themselves and in the markets of the world, are rapidly acquiring the knowledge that efficiency of production is a sounder basis for prosperity than mere volume of product, however great.

The long-continued and highly organised research which resulted in the development of American agricultural machinery has led to the general introduction of machines which reduce the labour cost of seven crops $681,000,000$ dollars, as measured by the methods of only fifty years ago.

You need not to be reminded that the ubiquitous telephone is wholly a product of American research. Munchausen's story of the frozen conversation which afterward thawed out is a clumsy fable. Think of the Niagaras of speech pouring silently through the New York telephone exchanges where they are sorted out, given a new direction, and delivered audibly perhaps a thousand miles away. New York has 450 ,0oo instruments - twice the number of those in London. Los Angeles has a telephone to every four inhabitants. Why should one care to project one's astral body when he can call up from the club in fifteen seconds? Our whole social structure has been reorganised. We have been brought together in a single parlour for conversation and to conduct affairs, because the American Telephone and Telegraph Company spends annually for research, the results of which are all about us, a sum greater than the total income of many universities.

The name of Edison is a household word in every language. The Edison method is a synonym for specialised, intense research, which knows no rest until everything has been tried. Because of that method and the unique genius which directs its application, Italian operas are heard amid Alaskan snows and in the depths of African forests; every phase of life and movement of interest throughout the world is caught, registered, transported, and reproduced, that we may have lion hunts. in our drawing-rooms and the coronation in a five-cent theatre. From his laboratory have come the incandescent lamp, multiple 